\title{
Long-Term Effects of Energy-Restricted Diets Differing in Glycemic Load on Metabolic Adaptation and Body Composition*
}

\author{
Sai Krupa Das*, ${ }^{1}$, Cheryl H. Gilhooly ${ }^{1}$, Julie K. Golden ${ }^{1}$, Anastassios G. Pittas ${ }^{2}$, Paul J. Fuss ${ }^{1}$, \\ Gerard E. Dallal ${ }^{1}$, Megan A. McCrory ${ }^{3}$, Edward Saltzman ${ }^{1}$ and Susan B. Roberts ${ }^{1}$ \\ ${ }^{1}$ Jean Mayer USDA Human Nutrition Research Center on Aging at Tufts University, Boston, MA, USA \\ ${ }^{2}$ Tufts - New England Medical Center Hospital, Boston, MA, USA \\ ${ }^{3}$ Department of Food and Nutrition, Department of Psychological Sciences, Purdue University, West Lafayette, IN, USA
}

\begin{abstract}
A randomized controlled trial of high glycemic load (HG) and low glycemic load (LG) diets with food provided for 6 months and self-administered for 6 additional months at 30\% caloric restriction (CR) was performed in 29 overweight adults (mean $\pm \mathrm{SD}$, age $35 \pm 5 \mathrm{y}$; BMI $27.5 \pm 1.5 \mathrm{~kg} / \mathrm{m}^{2}$ ). Total energy expenditure (TEE), resting metabolic rate (RMR), fat and fat free mass (FFM), were measured at 3, 6 and 12 months. Changes in TEE, but not changes in RMR, were greater than accounted for by the loss of FFM and fat mass $(\mathrm{P}=0.001-0.013)$ suggesting an adaptive response to long-term CR. There was no significant effect of diet group on change in RMR or TEE. However, in subjects who lost $>5 \%$ body weight $(\mathrm{n}=26)$, the LG diet group had a higher percentage of weight loss as fat than the HG group $(\mathrm{p}<0.05)$, a finding that may have implications for dietary recommendations during weight reduction.
\end{abstract}

Keywords: Glycemic load, caloric restriction, body weight, metabolic rate.

\section{INTRODUCTION}

The question of whether low glycemic index (GI) or low glycemic load (LG) diets facilitate greater weight loss and prevention of weight regain remains controversial, with some studies reporting benefits compared to high glycemic load (HG) diets [1-5] and other studies finding no such effect [5-10]. Further information on the effects of dietary GI and glycemic load (GL) on parameters related to long-term weight loss success is thus needed.

Information on the effects of HG and LG diets on metabolic adaptation and body composition may help determine whether one diet or the other is more beneficial for long-term weight control. Metabolic adaptation can be defined as a change in energy expenditure with weight gain or loss over and above that accounted for by the change in body fat free mass (FFM) and fat mass, and may potentially impact longterm weight loss success. Some studies have reported that metabolic adaptation occurs during weight loss and/or subsequently [11-18] while others have found no evidence for this phenomenon [19-25]. In part, the different results obtained may be due to different mathematical approaches to calculating metabolic adaptation, as well as the duration and severity of caloric restriction (CR) [26]. However, it is also possible that the macronutrient composition of the diets used may have influenced the results, as two recent short-term studies from the same group $[15,16]$ suggested greater

\footnotetext{
*Address correspondence to this author at the Energy Metabolism Laboratory, Room 1314A, Jean Mayer USDA Human Nutrition Research Center on Aging at Tufts University, 711 Washington St., Boston, MA 02111, USA; Tel: 617-556-3313; Fax: 617-556-3033; E-mail: sai.das@tufts.edu *Trial Registration: ClinicalTrials.gov Identifier: NCT00099099.
}

reductions in resting energy expenditure in subjects randomized to an energy-restricted $\mathrm{HG}$ diet compared to an LG diet.

Concerning the effects of GL on body composition, little information is currently available because most trials of dietary GL have reported only changes in body weight $[1,2,4-$ $6,8]$. One short-term study detected a non-significant trend toward a relative increase in nitrogen accretion in individuals consuming a LG diet compared to a HG diet [15], a finding consistent with a study in animals indicating relatively greater fat mass and lesser FFM after consumption of a HG diet compared [27] to a LG diet. However, another human study did not observe a significant difference in percent fat loss between individuals consuming HG and LG diets, [16] and thus further studies in this area are needed.

The objective of this study was to conduct further analyses on data from the first phase of the CALERIE (Comprehensive Assessment of the Long-term Effects of Restricting Intake of Energy) trial at Tufts University [10, 28], specifically to examine the effects of dietary GL on metabolic adaptation and the composition of weight loss during a 1 year CR intervention.

\section{SUBJECTS AND METHODS}

\section{Study Population and Protocol}

The subjects were 29 overweight but otherwise healthy men and women aged 24-42 years who completed the first phase of the CALERIE trial at Tufts University, having been randomized to the $30 \% \mathrm{CR}$ arm of the protocol. CALERIE is a coordinated multi-center study of CR in human health and aging, and during this first phase, independent studies were conducted at the different sites. Details of the study eligibility criteria as well as the protocol are described elsewhere 
$[10,28]$. Briefly, this year long intervention study included a 7-week baseline weight maintenance period (Phase 1), after which subjects were randomized to a $\mathrm{HG}$ load diet or a LG load diet and all food was provided at $70 \%$ of individual baseline weight maintenance energy requirements for 24weeks (Phase 2). A second level of short term interventions during Phase 2 of the study tested common variations in dietary protocols, and involved serial short-term randomizations to: i) 6-week period of extra fiber ( $20 \mathrm{~g}$ /day from a high fiber breakfast cereal) or no extra fiber at 5-10 weeks of caloric restriction, and ii) a 6-week period at 15-20 weeks of caloric restriction when subjects were either offered or not offered the option of substituting $1000 \mathrm{kcal} /$ week of food of their own choosing for $1000 \mathrm{kcal} /$ week of study food. Both options were available to all participants after the randomization period. Neither of these secondary randomizations had significant effects on energy intake, body weight change or dietary satisfaction within the randomization period, and neither had a significant interaction in the analyses testing the effects of the primary randomization on body weight and other main outcomes at 6 or 12 months. Phase 3 occurred over the next consecutive 24 weeks, when subjects were given regular instruction in how to take over all responsibility for food preparation to continue their regimen at home. The study was conducted at the Jean Mayer USDA Human Nutrition Research Center on Aging at Tufts University with approval by the Institutional Review Board of Tufts-New England Medical Center Hospital. All subjects gave written, informed consent prior to participating, and were provided with a stipend.

\section{Study Diets}

Details of the study diets have been described elsewhere $[10,28]$. The diets differed in macronutrients and glycemic load (HG: $60 \%$ carbohydrate, $20 \%$ fat, $20 \%$ protein with a glycemic load of $118.3 \pm 4.1 \mathrm{~g} / 1000 \mathrm{kcal} v s \mathrm{LG}$ : $40 \%$ carbohydrate, $30 \%$ fat, $30 \%$ protein with a glycemic load of $45.4 \pm 4.6 \mathrm{~g} / 1000 \mathrm{kcal})$ and the carbohydrate sources in the LG diet were lower in GI based on published GIs of different foods [29]. Also as described previously [10], the diets contained equivalent amounts of fiber and had similar energy density. Since the largest difference between the diets is in GL, the diets are described as HG and LG diets. Daily Glycemic Load = daily GI $\mathrm{x}$ total available carbohydrate (g) for day) $/ 1000 \mathrm{kcal}$ (and available carbohydrate for each food $=$ total grams carbohydrate - total dietary fiber). Please note that although technically it would have been possible to change GL between the diets by changing just carbohydrate and fat (and leaving protein constant), in that approach it would have been hard to control other factors between the diets including palatability and energy density. Using the chosen approach, it was possible to match the diets for dietary variety, and palatability (assessed using a visual analog scale, VAS, during pilot testing of the diets). All subjects were also provided with one half of a multivitamin supplement and $500 \mathrm{mg} /$ day of calcium.

All food was provided at the $30 \%$ reduced CR prescription to subjects during the first 6 months of the CR intervention. Subjects were asked to consume only the provided food and were requested to bring back their leftover foods from the provided foods and these were weighed and the amounts were recorded on the data recording sheets. Allowances were made on days such as Thanksgiving and Christmas (or other infrequent special requests) and subjects were given nonperishable foods and menu suggestions when traveling. Intake was self-recorded during these times. Subjects or their designated representative came to the research center twice a week to pick up meals.

During the second 6 months, subjects were instructed to self-select and prepare their own food at home to maintain their randomization. To prepare for this phase, subjects worked with the study dietitian to develop an individualized plan which included menus, recipes, portion sizes and food lists that were consistent with their randomized diets, prescribed calorie levels, and food preferences. Food scales were provided to help with appropriate portioning and subjects participated in a preparatory grocery store tour and cooking class.

\section{Body Weight and Height}

Body weight was measured at weekly intervals to $\pm 0.01 \mathrm{~kg}$ (DETECTO-Cardinal Scale Manufacturing Co. Model CN-20, Webb City, MO). Height was measured during baseline using a wall-mounted stadiometer.

\section{Body Composition}

Body composition was measured in duplicate at baseline and at 3, 6 and 12 months using air displacement plethysmography (BOD POD ${ }^{\circledR}$, Life Measurement, Inc, Concord, $\mathrm{CA})$. The details of this method and the underlying principles were described previously $[30,31]$. Briefly, measurements were conducted with the subject in a Lycra-style swim cap and minimal skin-tight shorts or underwear while subjects were dry and in the resting state according to the manufacturer's instructions. Body weight was measured to the nearest $1 \mathrm{~g}$ on the instrument's electronic scale that was calibrated daily. After the standard calibration of the plethysmograph's chamber, subjects entered the chamber for measurements of raw body volume and thoracic gas volume $\left(\mathrm{V}_{\mathrm{TG}}\right) \cdot \mathrm{V}_{\mathrm{TG}}$ measurements were repeated until a figure of merit value less than 1.0 (signifying compliance) was obtained for all subjects. The obtained $\mathrm{V}_{\mathrm{TG}}$ and the average of two raw body volume measurements that agreed within 0.2 $\%$ was used in subsequent calculations. Body density was calculated as body weight/body volume, where body volume was corrected for $\mathrm{V}_{\mathrm{TG}}$ and a surface area artifact as described previously [31]. Body weight and the corrected body volume were used to calculate body density, and body fat percent was derived using the two-compartment Siri formula [32]. Calculations were performed by the BOD POD's software (version 2.14). Percentage of weight lost as fat and FFM was calculated using the body composition variables derived from this method. The test-retest coefficient of variation for percent body fat measured by BOD POD in human adults is $1.7 \% \pm 1.1 \%[30]$.

\section{Resting Metabolic Rate (RMR)}

RMR was measured on two mornings at baseline and at 6 months and 12 months of CR, after the subject slept overnight in the research center and fasted for 12 hours according to our usual procedures [10]. Measurements were obtained with subjects resting supine in comfortable thermo neutral conditions by indirect calorimetry (Deltatrac portable metabolic cart, Sensor Medics Corp., Yorba Linda, CA) and sub- 
jects were instructed to relax and avoid hyperventilation, fidgeting or sleeping during measurements. Measurements of oxygen consumed $\left(\mathrm{VO}_{2}\right)$ and carbon dioxide produced $\left(\mathrm{VCO}_{2}\right)$ were obtained for 40 minutes, and the last $30 \mathrm{~min}-$ utes of the data were used to calculate RMR using de Weir's equation [33]. The calorimeter was assessed periodically with an alcohol burn test to ensure that the accuracy of the measurements was within $\pm 1 \%$.

\section{Total Energy Expenditure (TEE)}

TEE of the subjects was measured in duplicate over successive 14-day periods at baseline and additional 14-day measurements were made at 3,6 and 12 months of CR. This standard, non-radioactive isotopic method has been extensively validated and is described elsewhere [34, 35]. Briefly, at the start of each TEE measurement, subjects fasted overnight and were given an oral dose of doubly labeled water $\left({ }^{2} \mathrm{H}_{2}{ }^{18} \mathrm{O}\right)$ containing $0.22 \mathrm{~g} \mathrm{H}_{2}{ }^{18} \mathrm{O} / \mathrm{kg}$ total body water and $0.115 \mathrm{~g}$ of ${ }^{2} \mathrm{H}_{2} \mathrm{O} / \mathrm{kg}$ total body water following collection of 2 independent baseline urine specimens. Subjects were then required to remain fairly sedentary and not to consume any food or water while urine samples were collected from complete voids made at 3, 4.5 and 6 hours after dose administration. After completion of urine collections, subjects were discharged from the unit and carried out their usual daily activities for 14 days, with supervised urine specimen collection on days 7 and 14. All samples were aliquoted in duplicates into airtight storage tubes (Sarstedt - No 62.547.004) immediately after collection, and stored at $-20{ }^{\circ} \mathrm{C}$.

Abundances of $\mathrm{H}_{2}{ }^{18} \mathrm{O}$ and ${ }^{2} \mathrm{H}_{2} \mathrm{O}$ in dilutions of the isotope doses and in urine specimens were measured in duplicate using isotope ratio mass spectrometry [36] and deuterium was prepared for analysis using an automated chromium reduction system [37]. The urine samples were analyzed at the Pennington Biomedical Research Center (Baton Rouge, LA). Isotope elimination rates $\left(\mathrm{k}_{\mathrm{h}}\right.$ and $\left.\mathrm{k}_{\mathrm{o}}\right)$ were calculated using linear regression of logged values, and $\mathrm{CO}_{2}$ production was calculated using the equations of Schoeller $e t$ al. [38], with the modifications by Racette et al. [39]. TEE was then calculated based on an assumed respiratory quotient (RQ) of 0.86. Please note that quite large errors in RQ have a small effect on the error of calculations of TEE [40].

Measurements of TEE obtained at 3,6 and 12 months during the $\mathrm{CR}$ intervention were used to calculate the actual energy intake of the subjects at these time periods. Since energy intake is equal to TEE plus change in energy balance (when a subject is not in neutral energy balance), TEE data can be used to calculate a value for energy intake unbiased by subject reporting, by correcting for the estimated change in body energy stores during the same period based on weight change [41]. Individual values for weight change during the DLW period were calculated from the regression of daily measurements of body weight made for up to 7 days before and 7 days after the period of TEE measurements (for maximum of 28 days). The energy content of weight change was calculated assuming a energy content of weight loss of $7.4 \mathrm{kcal} / \mathrm{g}$ [26].

\section{Statistics}

Statistical analyses were performed using SAS for Windows (version 9.1, SAS Institute, Cary, NC). Values are expressed as mean \pm SD unless otherwise specified. Two dif- ferent mathematical approaches were used to examine metabolic adaptation because different approaches can give different results and there is no consensus about which, if any, procedure is more valid. The first approach used paired $t$ tests to compare measured and predicted values for RMR and TEE for each individual at 3, 6 and 12 months of CR. Predicted RMR values were determined from regression equations developed using i) baseline FFM alone, and ii) using both baseline FFM and fat mass, as independent variables. Predicted TEE values were determined from regression equations developed using i) baseline body weight, and ii) using both baseline FFM and fat mass, as independent variables. The second approach to examining metabolic adaptation in RMR was to compute changes in RMR from baseline to 3, 6 and 12 months of CR adjusted for changes in FFM and fat mass using mixed model regression analyses. Mixed models were also used to examine differences between diet groups in percent changes from baseline in RMR, TEE, RQ and PAL. Independent sample t-tests were used to examine the differences in percent of weight lost as fat mass and as FFM. For this analysis we used data for all subjects with complete data $(\mathrm{N}=29 ; 15 \mathrm{HG}, 14 \mathrm{LG})$ as well as a subset of subjects $(\mathrm{N}=26 ; 13 \mathrm{HG}, 13 \mathrm{LG})$, with weight loss $>5 \%$ at 6 months. The justification for analyzing the subset was: i) individuals with $<5 \%$ weight loss were non-adherent to the dietary regimens and thus their inclusion would include individuals who were non-compliant and eating other foods of unknown composition as well as the provided diet; ii) there are inherent methodological errors in body composition assessment that are substantial for small amounts of weight loss. All P values were two-sided and a $\mathrm{P}$ value of 0.05 or less was considered to indicate statistical significance.

\section{RESULTS}

There were no statistically significant differences between the diet groups for any of the baseline variables as shown in Table $\mathbf{1}$.

Table 1. Baseline Subject Characteristics ${ }^{a}$

\begin{tabular}{|l|l|l|}
\hline & HG Diet & LG Diet \\
\hline \hline Age (y) & $35 \pm 5$ & $35 \pm 6$ \\
\hline Gender & & \\
\hline Males & 3 & 3 \\
\hline Females & 12 & 11 \\
\hline Height $(\mathrm{cm})$ & $168.7 \pm 11.0$ & $168.2 \pm 10.6$ \\
\hline Weight $(\mathrm{kg})$ & $78.5 \pm 12.3$ & $78.0 \pm 9.4$ \\
\hline BMI (kg/m $\left.{ }^{2}\right)$ & $27.4 \pm 1.7$ & $27.5 \pm 1.3$ \\
\hline$\%$ Body Fat & $35.0 \pm 7.1$ & $35.2 \pm 8.7$ \\
\hline Fat free mass (kg) & $51.2 \pm 11.3$ & $50.7 \pm 10.5$ \\
\hline RMR (MJ/day) & $6.62 \pm 1.1$ & $6.72 \pm 0.8$ \\
\hline Resting RQ & $0.85 \pm 0.02$ & $0.84 \pm 0.04$ \\
\hline TEE (MJ/day) & $12.10 \pm 2.3$ & $11.71 \pm 1.5$ \\
\hline
\end{tabular}

${ }^{a}$ Values are means \pm SD. HG - high glycemic load diet $(\mathrm{N}=15), \mathrm{LG}$ - low glycemic load diet $(\mathrm{N}=14)$, RQ - respiratory quotient. Using independent sample t-tests, no statistically significant differences were observed between the diet groups for the baseline variables. 


\section{Metabolic Adaptation in Relation to Weight Change and Diet Randomization}

Fig. (1) shows data for the measured and predicted RMR at 3, 6 and 12 months of $\mathrm{CR}$, with predicted values calculated as described in the statistics section above. At baseline, both FFM and fat mass significantly and positively predicted RMR $\left(\mathrm{R}^{2}=0.81, \mathrm{P}<0.001\right)$. At all time points during the intervention, the correlation between predicted and measured RMR was higher when the regression equation included both FFM and fat mass as independent variables versus when only FFM was used. When only FFM was used in the regression equation, predicted RMR was significantly higher than measured RMR $(\mathrm{P}<0.0001$ at 3 months; $\mathrm{P}=0.003$ at 6 months and $\mathrm{P}=0.001$ at 12 months) but when both FFM and fat mass were used there was no significant difference between meas-

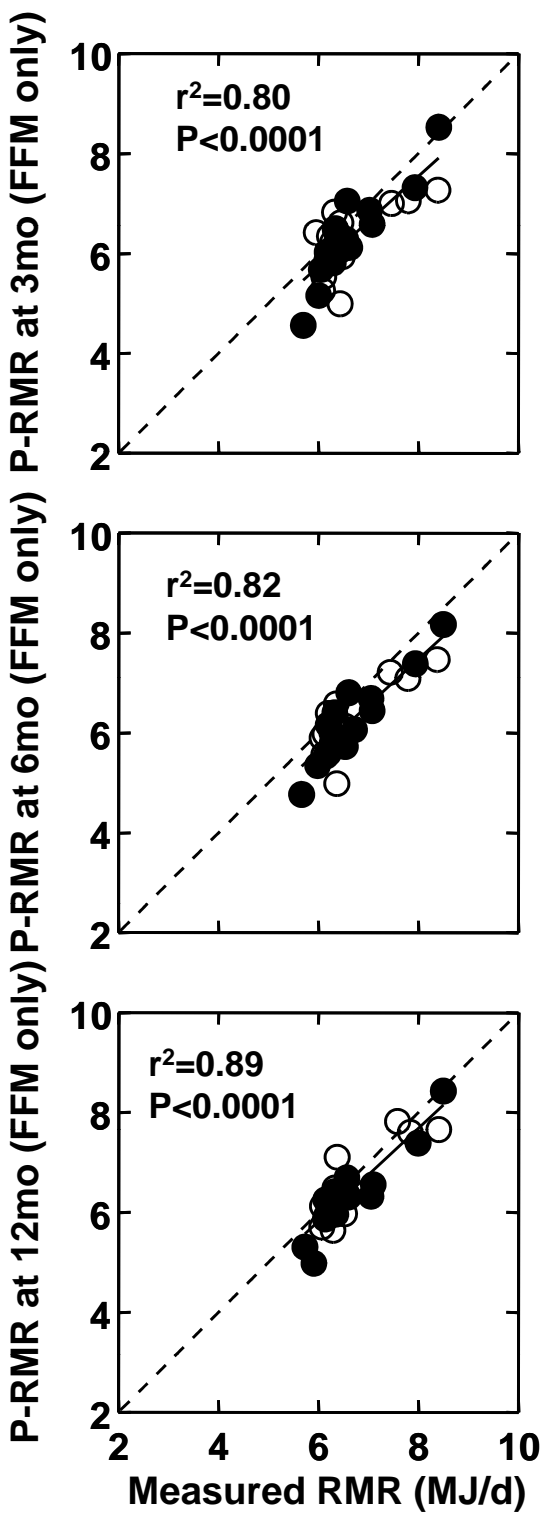

ured and predicted $\mathrm{RMR}$ at any time point $(\mathrm{P}=0.36$ at 3 months; $\mathrm{P}=0.22$ at 6 months and $\mathrm{P}=0.25$ at 12 months). There was also no significant effect of diet group on the difference between measured RMR and RMR predicted from FFM alone or from FFM and fat mass at any time point $(\mathrm{P}=0.19-0.95)$.

Fig. (2) shows measured versus predicted TEE, with predicted values calculated as described in Statistics. At all time points during $\mathrm{CR}$, measured TEE was significantly lower than TEE predicted from fat and FFM $(\mathrm{P} \leq 0.01)$ but not significantly different from TEE predicted from body weight $(\mathrm{P}=0.40-0.44)$. With regards to diet groups effects on TEE, the difference between measured TEE and TEE predicted from FFM and fat mass was significantly higher $(\mathrm{P}=0.02)$ in the LG group only at 3 months, and this difference was not
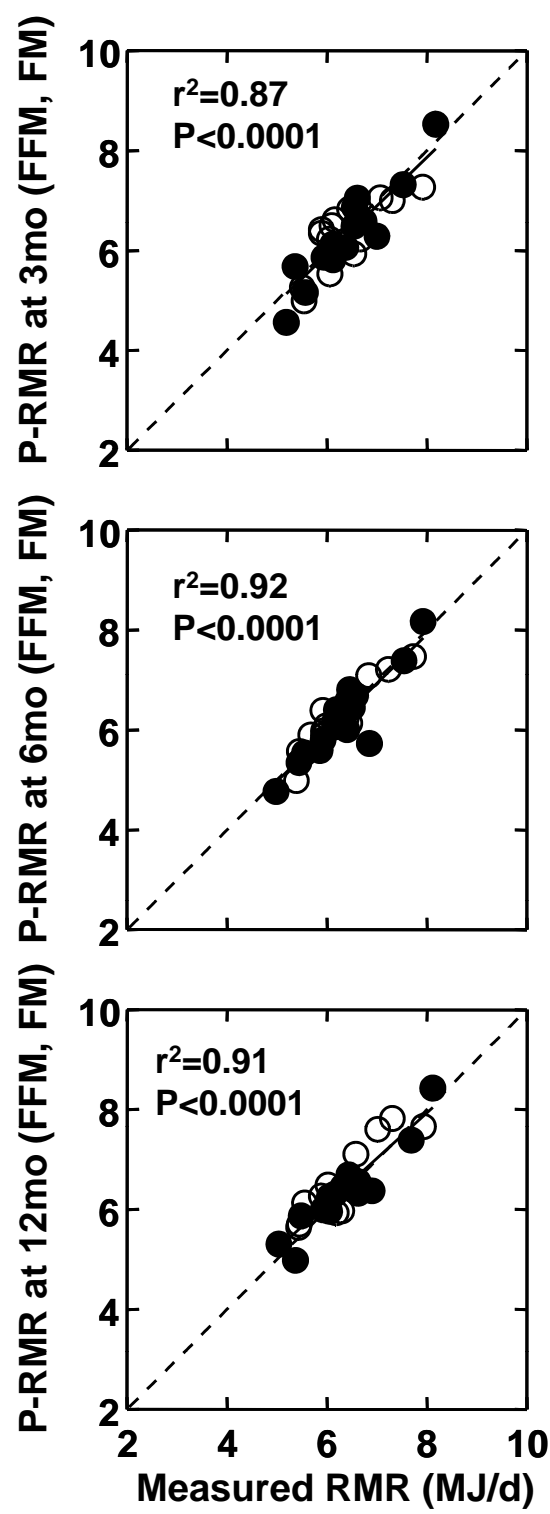

Fig. (1). Correlation between measured resting metabolic rate (RMR) and RMR predicted using fat free mass (FFM) alone or both FFM and fat mass at 3, 6 and 12 months of caloric restriction. Predicted RMR, (P-RMR) was determined using equations developed with baseline FFM only or FFM and fat mass.

RMR predicted from FFM alone was significantly higher than measured RMR at all time points $(\mathrm{P}<0.0001$ at 3 months; $\mathrm{P}=0.003$ at 6 months and $\mathrm{P}=0.001$ at 12 months) but RMR predicted from FFM and fat mass was not significantly different from measured RMR at all time points ( $\mathrm{P}=0.36$ at 3 months; $\mathrm{P}=0.22$ at 6 months and $\mathrm{P}=0.25$ at 12 months). 

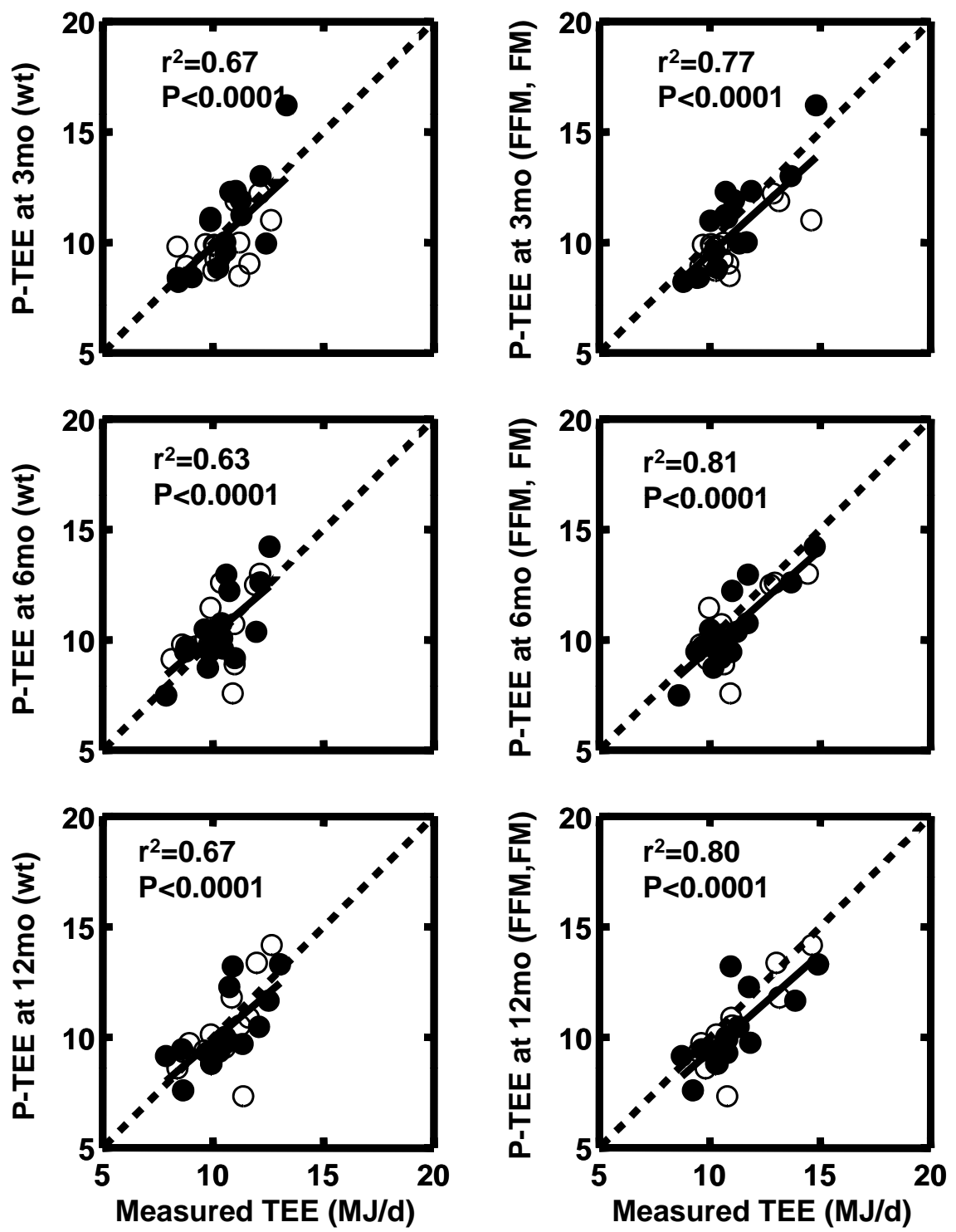

Fig. (2). Correlation between measured total energy expenditure (TEE) and TEE predicted using body weight or using fat free mass (FFM) and fat mass at 3,6 and 12 months of caloric restriction. Predicted TEE, (P-TEE) was determined using equations developed with baseline body weight or FFM and fat mass. TEE predicted from body weight alone was not significantly higher than measured TEE at all time points ( $\mathrm{P}=0.44$ at 3 months; $\mathrm{P}=0.42$ at 6 months and $\mathrm{P}=0.40$ at 12 months) but TEE predicted from FFM and fat mass was significantly different from measured TEE at all time points $(\mathrm{P}=0.007$ at 3 months; $\mathrm{P}=0.013$. at 6 months and $\mathrm{P}=0.001$ at 12 months).

statistically significant long-term at the 6 month $(\mathrm{P}=0.84$ 0.96) and 12 month $(\mathrm{P}=0.84-0.96)$ time points.

The results of the second approach to examining metabolic adaptation are shown for RMR in Table 2. The RMR results were very similar to those obtained in the first exploration of metabolic adaptation. The decrease in RMR at 3 and 6 months was significant after accounting for the change in FFM alone but not significant after the change in fat mass was also accounted for. At month 12 of CR, the decrease in RMR was not significant after adjusting for either the change in FFM only or the combined changes in FFM and fat mass. There was no significant effect of diet randomization on change in RMR with CR. With regards to diet group effects on TEE using this approach, there was no significant effect of diet randomization on change in TEE both in the short term i.e., at 3 months and also at the 6 and 12 month time points $(P=0.20-0.70$, data not shown $)$.
Fig. (3) shows the percent change in RMR, TEE, RQ and PAL for the two diets. No statistically significant differences between the diet groups were seen for any variable at any time point $(\mathrm{P}$ values for diet*time interaction: $\mathrm{P}=0.40$ for $\mathrm{RMR}, \mathrm{P}=0.10$ for TEE, $\mathrm{P}=0.95 \mathrm{RQ}$ and $\mathrm{P}=0.18$ for $\mathrm{PAL}$ ). Mean PAL was $1.79 \pm 0.18$ at baseline and $1.68 \pm 0.16$ and $1.60 \pm 0.17$ at 6 and 12 months of CR, respectively, in all subjects combined.

\section{Composition of Weight Loss in Relation to Weight Loss and Diet Randomization}

Percentage of weight lost as fat and FFM was calculated from baseline to 6 months, when all food was provided and adherence was highest [10]. There was no significant difference in the mean percent weight loss between the groups at 6 or 12 months of CR $(-9.6 \pm 3.8$ for HG $v s-10.9 \pm 4.2$ for LG at 12 months) [10]. When the subset of subjects with weight 
Table 2. Regression Models Predicting Change in Resting Metabolic Rate from the Change in Body Composition

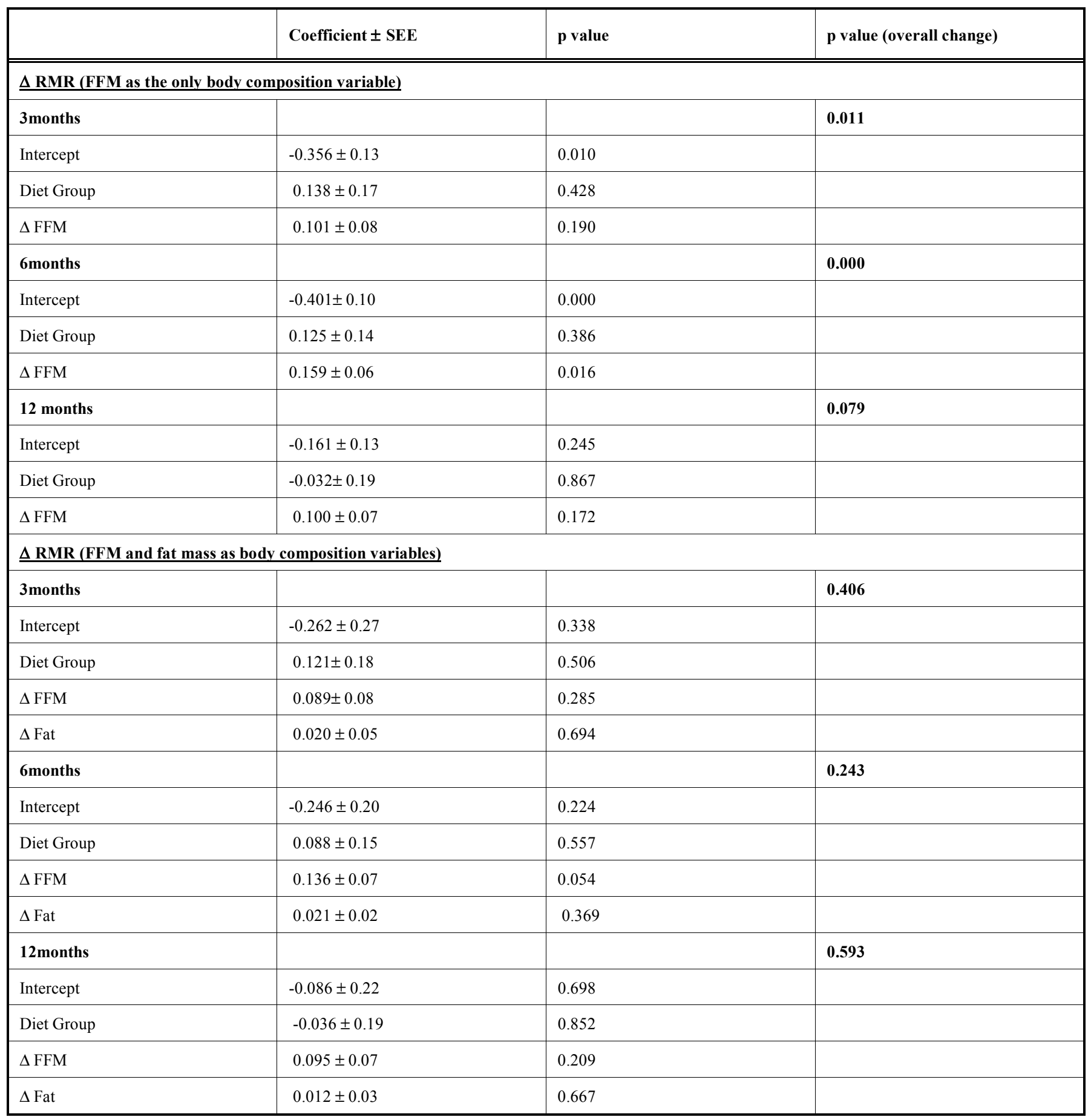

RMR, resting metabolic rate (MJ/d), FFM, fat free mass (kg), Diet group - high glycemic load, low glycemic load diets. Using mixed model analysis of regression changes in RMR were examined at 3,6 and 12 month time points after accounting for changes in FFM and fat mass.

loss $>5 \%$ were compared (justified in Statistics, above; also we only lost 3 subjects for this subset analysis $N=26$ : 13 HG, 13 LG), the LG group had a significantly higher percentage of weight loss as fat (98.5 vs 87.4) and a significantly lower percentage of weight loss as FFM (1.50 vs 12.6; $\mathrm{P}=0.047 ; 95 \% \mathrm{CI}=0.14-22.15)$ (Fig. 4). This difference in percentage of weight loss as fat approached significance $(\mathrm{P}=0.063)$ at 6 months when all subjects were included in the analysis. At 12 months when subjects were on self-selected foods and adherence to the prescription was lower, the dif- ference in percent of weight loss as fat and FFM was not significant in the whole sample $(\mathrm{P}=0.16)$ and no longer significant in the subset $(\mathrm{P}=0.44)$.

\section{DISCUSSION}

The role of dietary carbohydrate in successful weight loss and prevention of weight regain remains very controversial. Both total carbohydrate and carbohydrate type (as quantified by the GL and GI, respectively) have been studied for their effects on hunger and satiety [42-45], and weight loss and 

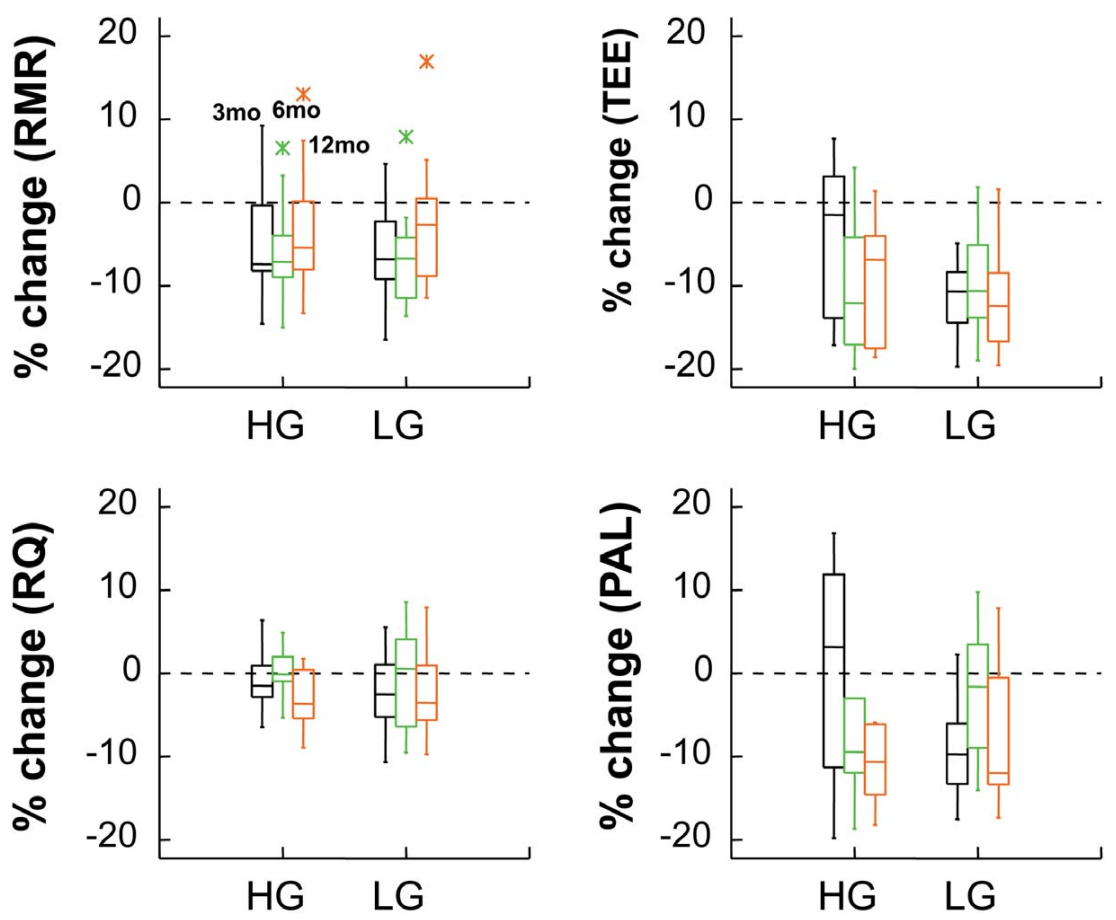

Fig. (3). Mean and variability in percent changes in resting metabolic rate (RMR), total energy expenditure (TEE), respiratory quotient (RQ) and physical activity level (PAL) at 3, 6 and 12 months of caloric restriction in subjects randomized to the high glycemic (HG) and low glycemic (LG) diets. There was no significant difference in the percent change over time from baseline in any parameter (P values for diet*time interaction: $\mathrm{P}=0.40$ for $\mathrm{RMR}, \mathrm{P}=0.10$ for TEE, $\mathrm{P}=0.95$ RQ and $\mathrm{P}=0.18$ for $\mathrm{PAL}$ ).

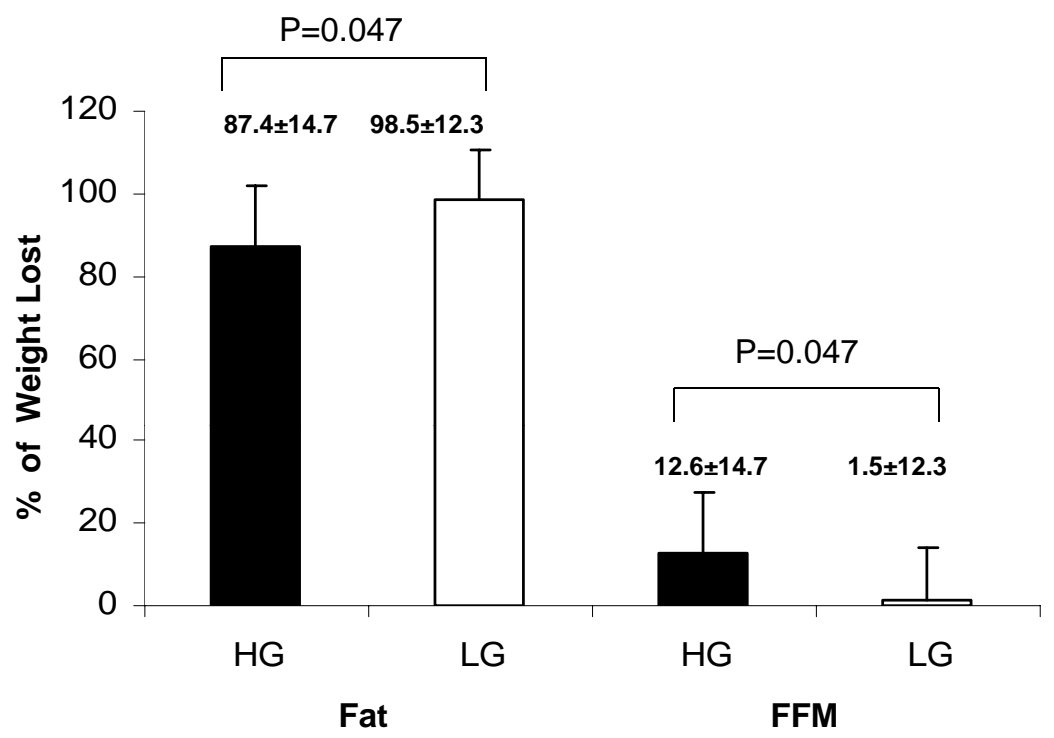

Fig. (4). Percent of weight lost as fat and fat free mass (FFM) on the high glycemic (HG) $\mathbf{a}$ and low glycemic (LG) $\square$ diets at 6 months of caloric restriction. $\mathrm{N}=13 \mathrm{HG}, 13 \mathrm{LG}$; analysis excludes 3 subjects with weight loss $<5 \%$ of initial weight as measured at 6 months.

prevention of weight gain $[5-7,10,46]$. Single-meal and other short-term studies generally document beneficial effects of low carbohydrate diets and low GI diets on hunger and satiety [43, 44], but most longer-term studies have reported no significant difference in weight loss or weight regain $[5-7,10]$. Given the ongoing lack of consensus in this area, we evaluated the effects of HG and LG diets on metabolic adaptation and body composition change, reasoning that a finding of differences in these parameters could contribute to the ongoing debate about optimal carbohydrate intake for long-term weight control. The results of our study indicate no effect of LG versus HG diets on metabolic adaptation to $\mathrm{CR}$, but tentatively suggest significantly greater fat content of weight loss in individuals consuming LG diets.

Some strengths and weaknesses of this study should be noted. First, most previous studies of dietary carbohydrate and energy regulation have either been very short-term studies providing food [15, 47-49] or long-term studies in which subjects were counseled on regimens for self-administration $[1,50,51]$. Dietary intake in the present study was uniquely 
controlled because all food was provided to volunteers for 6 months and documented adherence to the regimen was high when food was provided [10], thus allowing us to relate metabolic adaptation and body composition change to more reliable dietary intake information than is usually possible. On the other hand, since the primary focus was on the GL we tested diets with different macronutrient balances and the results cannot be attributed with certainty to one particular nutrient. Also the population studied was relatively small and our sample size was further reduced for the body composition analyses and therefore further studies are needed in larger populations.

The first finding in the study was that there was no difference in long-term metabolic adaptation to weight loss between individuals randomized to $\mathrm{HG}$ and $\mathrm{LG}$ regimens. On theoretical grounds, the dietary GL has the potential to influence energy expenditure and, hence, metabolic adaptation. HG diets have been demonstrated to cause greater fluctuations in circulating metabolic fuels [52], and metabolic fuel availability is a known contributor to variability in metabolic rate [53, 54]. To our knowledge, only two studies have been conducted on dietary GL and energy expenditure, both by the same group $[15,16]$. Results in both studies suggested that LG diets were associated with smaller reductions in resting energy expenditure, indicating reduced metabolic adaptation, and therefore potentially greater weight loss. The reason for the difference between our study and the previous ones is not known. Our results were obtained using two different mathematical approaches and at 3 different time points, suggesting that the results are not an artifact of the method of calculation or time of assessment. We speculate that one explanation might be the lack of differences in hunger between our study diets, in view of recent speculations that metabolic adaptation and hunger may be closely linked [55]. Both of our diets were relatively high in fiber and low in energy density, factors which have been linked to reduced hunger and adequate satiety [56, 57].

With regard to metabolic adaptation in response to weight loss more generally, we did not find a greater than anticipated reduction in the RMR component at any time point when changes in both FFM and fat mass were taken into account. Previous studies have reported both metabolic adaptation to weight loss [14-17] and no metabolic adaptation [19-23], and factors such as ongoing weight loss and lack of accounting for body fat change as well as FFM change may help explain the variability in results [26]. However, in our study, TEE was lower than expected based on the changes in fat and FFM (at 12 months of CR by approximately $0.76 \mathrm{MJ} / \mathrm{d}(180 \mathrm{kcals} / \mathrm{d})$, equivalent to $6.6 \%$ of baseline TEE) suggesting an adaptive response to the longterm CR that may contribute to the recognized risk of weight regain following weight loss in mildly overweight individuals such as those studied here [58].

The other main finding of this study was that weight loss at the end of the food provided phase (month 6) contained a higher percentage of fat and a lower percentage of FFM in subjects randomized to the LG diet compared to the HG diet. The finding approached significance when all subjects were included in the analysis, and was significant when three subjects with $<5 \%$ weight loss were excluded on the grounds that such subjects were not consuming the dietary prescrip- tion. This finding is consistent with a previous study reporting a non-significant reduced nitrogen loss [15] in individuals consuming LG diets compared to $\mathrm{HG}$ diets, and one study in an animal model [27]. The observed difference may be attributed to the anabolic effects of the increased circulating post-prandial insulin associated with the consumption of $\mathrm{HG}$ diets which favors fat deposition through increase in lipogenesis [59] and also to the higher protein content of our LG diets which may have favored a reduced loss of FFM as suggested by some but not all studies of protein intake and FFM [60].

\section{CONCLUSION}

This 1-year study of healthy overweight adults found significantly reduced TEE beyond that expected for loss of FFM and fat mass during CR. There was no statistically significant difference in metabolic adaptation to the $\mathrm{HG}$ and LG diets but adherence to the LG regimen apparently caused greater loss of body fat and less loss of FFM for the same amount of overall weight loss. Additional studies are needed to confirm these findings, which suggest a beneficial effect of consuming LG diets for weight control independent of an effect on absolute weight loss.

$\begin{array}{ll}\text { ABBREVIATIONS } \\ \text { BMI } & =\text { Body Mass Index } \\ \text { CR } & \text { Caloric Restriction } \\ \text { CALERIE } & \text { Comprehensive Assessment of the Long- } \\ \text { term Effects of Restricting Intake of Energy } \\ \text { FFM } & =\text { Fat free mass } \\ \text { GL } & =\text { Glycemic Load } \\ \text { GI } & =\text { Glycemic Index } \\ \text { HG } & =\text { High glycemic load } \\ \text { LG } & =\text { Low glycemic load } \\ \text { RMR } & =\text { Resting metabolic rate } \\ \text { TEE } & =\text { Total energy expenditure } \\ \text { USDA } & =\text { United States Department of Agriculture }\end{array}$

\section{ACKNOWLEDGEMENTS}

We thank the subjects for their committed participation in this study, and the staff of the Metabolic Research Unit and the Nutrition Evaluation Laboratory for their expert assistance throughout the study.

\section{SUPPORT AND FUNDING}

This project work was supported by an NIH grant: NGA3U01-AG20480, and by the U.S. Department of Agriculture under agreement No. 58-1950-4-401, and the Boston Obesity Nutrition Research Center (BONRC) NIH grant \#H150001.

\section{REFERENCES}

[1] Foster GD, Wyatt HR, Hill JO, et al. A randomized trial of a lowcarbohydrate diet for obesity. N. Engl J Med 2003; 348(21): 208290 .

[2] Yancy WSJ, Olsen MK, Guyton JR, Bakst RP, Westman EC. A low-carbohydrate, ketogenic diet versus a low-fat diet to treat obesity and hyperlipidemia: a randomized, controlled trial. Ann Intern Med 2004; 140(10): 769-77. 
[3] Pittas AG, Das SK, Hajduk CL, et al. A low-glycemic load diet facilitates greater weight loss in overweight adults with high insulin secretion but not in overweight adults with low insulin secretion in the CALERIE Trial. Diabetes Care 2005; 28(12): 2939-41.

[4] Hare-Bruun H, Flint A, Heitmann BL. Glycemic index and glycemic load in relation to changes in body weight, body fat distribution, and body composition in adult Danes. Am J Clin Nutr 2006; 84(4): 871-9.

[5] Maki KC, Rains TM, Kaden VN, Raneri KR, Davidson MH. Effects of a reduced-glycemic-load diet on body weight, body composition, and cardiovascular disease risk markers in overweight and obese adults. Am J Clin Nutr 2007; 85(3): 724-34.

[6] Raatz SK, Torkelson CJ, Redmon JB, et al. Reduced glycemic index and glycemic load diets do not increase the effects of energy restriction on weight loss and insulin sensitivity in obese men and women. J Nutr 2005; 135(10): 2387-91.

[7] Dansinger ML, Gleason JA, Griffith JL, Selker HP, Schaefer EJ. Comparison of the Atkins, Ornish, Weight Watchers, and Zone diets for weight loss and heart disease risk reduction: a randomized trial. JAMA 2005; 293(1): 43-53.

[8] McMillan-Price J, Petocz P, Atkinson F, et al. Comparison of 4 diets of varying glycemic load on weight loss and cardiovascular risk reduction in overweight and obese young adults: a randomized controlled trial. Arch Intern Med 2006; 166(14): 1466-75.

[9] Pittas AG, Roberts SB, Das SK, et al. The effects of the dietary glycemic load on type 2 diabetes risk factors during weight loss. Obesity 2006; 14(12): 2200-9.

[10] Das SK, Gilhooly CH, Golden JK, et al. Long-term effects of two energy-restricted diets differing in glycemic load on dietary adherence, body composition and metabolism in CALERIE, a one year randomized controlled trial. Am J Clin Nutr 2007; 85: 1023-30.

[11] Ravussin E, Burnand B, Schutz Y, Jequier E. Energy expenditure before and during energy restriction in obese patients. Am J Clin Nutr 1985; 41: 753-9.

[12] Elliot D, Goldberg L, Kuehl KS, Bennett WM. Sustained depression of the resting metabolic rate after massive weight loss. Am J Clin Nutr 1989; 49: 93-6.

[13] Heshka S, Yang M-U, Wang J, Burt P, Pi-Sunyer FX. Weight loss and change in resting metabolic rate. Am J Clin Nutr 1990; 52: 981-6.

[14] Leibel RL, Rosenbaum M, Hirsch J. Changes in energy expenditure resulting from altered body weight. N Engl J Med 1995; 332: 621 8 .

[15] Agus MS, Swain JF, Larson CL, Eckert EA, Ludwig DS. Dietary composition and physiologic adaptations to energy restriction. Am J Clin Nutr 2000; 74(4): 901-7.

[16] Pereira MA, Swain J, Goldfine AB, Rifai N, Ludwig DS. Effects of a low-glycemic load diet on resting energy expenditure and heart disease risk factors during weight loss. JAMA 2004; 292(20): 2482-90.

[17] Heilbronn LK, de Jonge L, Frisard MI, et al. Effect of 6-month calorie restriction on biomarkers of longevity, metabolic adaptation, and oxidative stress in overweight individuals: a randomized controlled trial. JAMA 2006; 295(13): 1539-48.

[18] Major GC, Doucet E, Trayhurn P, Astrup A, Tremblay A. Clinical significance of adaptive thermogenesis. Int J Obes 2007; 3(12): 204-12.

[19] Wadden TA, Foster GD, Letizia KA, Mullen JL. Long-term effects of dieting on resting metabolic rate in obese outpatients. JAMA 1990; 264: 707-11.

[20] Jebb SA, Goldberg GR, Coward WA, Murgatroyd PR, Prentice AM. Effects of weight cycling caused by intermittent dieting on metabolic rate and body composition in obese women. Int $\mathrm{J}$ Obes 1991; 15(5): 367-74.

[21] Amatruda JM, Statt MC, Welle SL. Total and resting energy expenditure in obese women reduced to ideal body weight. J Clin Invest 1993; 92: 1236-42.

[22] Weinsier RL, Nelson KM, Hensrud DD, et al. Metabolic predictors of obesity. Contribution of resting energy expenditure, thermic effect of food, and fuel utilization to four-year weight gain of postobese and never-obese women. J Clin Invest 1995; 95(3): 980-5.

[23] Weinsier RL, Nagy TR, Hunter GR, et al. Do adaptive changes in metabolic rate favor weight regain in weight reduced individuals? An examination of the set point theory. Am J Clin Nutr 2000; 72 : 1088-94.
[24] Weinsier RL, Hunter GR, Zuckerman PA, et al. Energy expenditure and free-living physical activity in black and white women: comparison before and after weight loss. Am J Clin Nutr 2000; 71(5): 1138-46.

[25] Das SK, Roberts SB, McCrory MA, et al. Long-term changes in energy expenditure and body composition after massive weight loss induced by gastric bypass surgrey. Am J Clin Nutr 2003; 78: 22-30.

[26] Saltzman E, Roberts SB. The role of energy expenditure in energy regulation: findings from a decade of research. Nutr Rev 1995; 53(8): 209-20.

[27] Pawlak DB, Kushner JA, Ludwig DS. Effects of dietary glycaemic index on adiposity, glucose homoeostasis, and plasma lipids in animals. Lancet 2004; 364(9436): 778-85.

[28] Gilhooly CH, Das SK, Golden JK, et al. Use of cereal fiber to facilitate adherence to a human caloric restriction program. Aging Clin Exp Res 2008 (In press).

[29] Foster-Powell K, Holt SHA, Brand-Miller JC. International table of glycemic index and glycemic load values. Am J Clin Nutr 2002; 76: 5-56.

[30] McCrory MA, Gomez TD, Bernauer EM, Mole PA. Evaluation of a new air displacement plethysmograph for measuring human body composition. Med Sci Sports Exerc 1995; 27: 1686-91.

[31] Dempster P, Aitkens S. A new air displacement method for the determination of human body composition. Med Sci Sports Exerc 1995; 27: 1692-7.

[32] Siri WE. Body composition from fluid spaces and density: analysis of methods. In: Brozek J, Henschel A, Ed. Techniques for measuring body composition. National Academy of Sciences, NRC: Washington, D.C. 1961; 223-44.

[33] de Weir JB. New method for calculating metabolic rate with special reference to protein metabolism. J Physiol 1949; 109: 1-9.

[34] Roberts SB, Young VR, Fuss P, et al. Energy expenditure and subsequent nutrient intakes in overfed young men. Am J Physiol Endocrinol Metab 1990; 259(3 Pt 2): R461-9.

[35] Schoeller DA. Recent advances from application of doubly labeled water to measurement of human energy expenditure. J Nutr 1999; 129(10): 1765-8

[36] DeLany JP, Schoeller DA, Hoyt RW, Askew EW, Sharp MA. Field use of D2 180 to measure energy expenditure of soldiers at different energy intakes. J Appl Physiol 1989; 67(5): 1922-9.

[37] Schoeller DA, Colligan AS, Shriver T, Avak H, Bartok-Olson C. Use of an automated chromium reduction system for hydrogen isotope ratio analysis of physiological fluids applied to doubly labeled water analysis. J Mass Spectrom 2000; 35: 1128-32.

[38] Schoeller DA, van Santen E. Measurement of energy expenditure in humans by doubly labeled water method. J Appl Physiol 1982; 53: 955-9.

[39] Racette SB, Schoeller DA, Luke AH, et al. Relative dilution spaces of ${ }^{2} \mathrm{H}$ and ${ }^{18} \mathrm{O}$-labeled water in humans. Am J Physiol 1994; 267 : E585-E590.

[40] Surrao J, Sawaya AL, Dallal GE, Tsay R, Roberts SB. The use of food quotients in human doubly labeled water studies: Comparable results obtained with 4 widely used food intake methods. J Am Diet Ass 1998; 98(9): 1015-20.

[41] Bathalon GP, Tucker KL, Hays NP, et al. Psychological measures of eating behavior and the accuracy of three common diet methodologies in healthy postmenopausal women. Am J Clin Nutr 2000; 71: 739-45.

[42] Stubbs RJ, Mazlan N, Whybrow S. Carbohydrates, appetite and feeding behavior in humans. J Nutr 2001; 131(10): 2775S-81S.

[43] Roberts SB. Glycemic index and satiety. Nutr Clin Care 2003; 6(1): 20-6.

[44] Nickols-Richardson SM, Coleman MD, Volpe JJ, Hosig KW. Perceived hunger is lower and weight loss is greater in overweight premenopausal women consuming a low-carbohydrate/high-protein vs high-carbohydrate/low-fat diet. J Am Diet Assoc 2005; 105(9): 1433-7.

[45] Cotton JR, Burley VJ, Weststrate JA, Blundell JE. Dietary fat and appetite: similarities and differences in the satiating effect of meals supplemented with either fat or carbohydrate. J Hum Nutr Diet 2007; 20(3): 186-99.

[46] Ebbeling CB, Leidig MM, Feldman HA, Lovesky MM, Ludwig DS. Effects of a low-glycemic load vs low-fat diet in obese young adults: a randomized trial. JAMA 2007; 297(19): 2092-2102. 
[47] Agus MS, Eckert EA, Larson CL, Swain JF, Ludwig DS. The effects of dietary composition on the physiologic responses to calorie deprivation. Pediatr Res 1999; 45: A481.

[48] Green SM, Wales JK, Lawton CL, Blundell JE. Comparison of high-fat and high-carbohydrate foods in a meal or snack on shortterm fat and energy intakes in obese women. Br J Nutr 2000; 84(4): 521-30.

[49] Kaplan RJ, Greenwood CE. Influence of dietary carbohydrates and glycaemic response on subjective appetite and food intake in healthy elderly persons. Int J Food Sci Nutr 2002; 53(4): 305-16.

[50] Stern L, Iqbal N, Seshadri P, et al. The effects of low-carbohydrate versus conventional weight loss diets in severely obese adults: oneyear follow-up of a randomized trial. Ann Intern Med 2004; 140(10): 778-85.

[51] Klein S. Clinical trial experience with fat-restricted $v s$ carbohydrate-restricted weight-loss diets. Obes Res 2004; 12 (Suppl 2): $141 \mathrm{~S}-4 \mathrm{~S}$.

[52] Ludwig DS, Majzoub JA, Al-Zahrani A, et al. High glycemic index foods, overeating, and obesity. Pediatrics 1999; 103: E261-E266.

[53] Labayen I, Diez N, Parra MD, Gonzalez A, Martinez JA. Timecourse changes in macronutrient metabolism induced by a nutri- tionally balanced low-calorie diet in obese women. Int J Food Sci Nutr 2004; 55(1): 27-35.

[54] Marrades MP, Martinez JA, Moreno-Aliaga M. Differences in short-term metabolic responses to a lipid load in lean (resistant) $v s$ obese (susceptible) young male subjects with habitual high-fat consumption. Eur J Clin Nutr 2007; 61(2): 166-74.

[55] Speakman JR, Hambly C. Starving for life: what animal studies can and cannot tell us about the use of caloric restriction to prolong human lifespan. J Nutr 2007; 137(4): 1078-86.

[56] Howarth NC, Saltzman E, Roberts SB. Dietary fiber and weight regulation. Nutr Rev 2001; 59(5): 129-39.

[57] Yao M, Roberts SB. Dietary energy density and weight regulation. Nutr Rev 2001; 59(8 Pt 1): 247-58.

[58] Jeffery RW, Drewnowski A, Epstein LH, et al. Long-term maintenance of weight loss: current status. Health Psychol 2000; 19(1 Suppl): 5-16.

[59] Unger RH. Reinventing type 2 diabetes: pathogenesis, treatment, and prevention. JAMA 2008; 299(10): 1185-7.

[60] Eisenstein J, Roberts SB, Dallal G, Saltzman E. High-protein weight-loss diets: are they safe and do they work? A review of the experimental and epidemiologic data. Nutr Rev 2002; 60: 189-200.

(C) Das et al.; Licensee Bentham Open.

This is an open access article licensed under the terms of the Creative Commons Attribution Non-Commercial License (http://creativecommons.org/licenses/by-nc/3.0/) which permits unrestricted, non-commercial use, distribution and reproduction in any medium, provided the work is properly cited. 